Original Research Article

\title{
A prospective study on causality, severity and preventability assessment of adverse drug reactions in a tertiary care hospital in India
}

\author{
Mahesh N. Belhekar¹, Sweta B. Tondare ${ }^{2}$, Prasad R. Pandit ${ }^{2}$, Kiran A. Bhave ${ }^{2}$, Tejal C. Patel ${ }^{2 *}$
}

${ }^{1}$ Department of Clinical Pharmacology, Seth GS Medical College and KEM Hospital, Parel, Mumbai, Maharashtra, India

${ }^{2}$ Department of Pharmacology, HBT Medical College and Dr RN Cooper Mun. Gen. Hospital, Juhu, Mumbai, Maharashtra, India

Received: 12 October 2018 Accepted: 01 November 2018

\section{*Correspondence to: \\ Dr. Tejal C. Patel, \\ Email: drtejalchetan@ gmail.com}

Copyright: (C) the author(s), publisher and licensee Medip Academy. This is an openaccess article distributed under the terms of the Creative Commons Attribution NonCommercial License, which permits unrestricted noncommercial use, distribution, and reproduction in any medium, provided the original work is properly cited.

\begin{abstract}
Background: The present study was undertaken to evaluate the incidence and pattern of adverse drug reaction (ADRs), causality, severity and preventability of ADRs.

Methods: Data was collected and analyzed with the information such as patients' demographic details, associated co-morbid conditions and detailed drug related information gathered from ADR reporting forms. World Health Organization (WHO) scale was used for assessing causality, modified Hartwig scale was used for assessing severity and modified Schumock and Thorntons scale were used for assessing preventability of ADRs. Data was analyzed using descriptive statistics. Results: Total 154 ADRs were reported in a period of one year (August 2016July 2017). Out of 154 ADRs analyzed, 120 (77.9\%) were in adults, 33 (21.4\%) pediatric and $01(0.7 \%)$ in geriatric patients. The most common ADR recorded was cutaneous reactions $(43.5 \%)$ and the most common causative class of drugs for the same was found to be antimicrobials $(46.7 \%)$ followed by non-steroidal anti-inflammatory drugs (15.6\%). Causality assessment scale indicated $68.8 \%$ ADRs possible and $24 \%$ ADRs as probable. Severity assessment revealed that $45.5 \%$ were mild, $50.6 \%$ moderate and $3.9 \%$ ADRs severe. Preventability assessment showed $84.4 \%$ of the cases were probably non-preventable.

Conclusions: In this study it was found that, most of the ADRs were of possible category with mild to moderate severity and majority being non-preventable. Antimicrobial drugs being the most common offending drug class causing ADRs. Strategies targeting appropriate and cautious use of this class of drugs may benefit in reducing the number of ADRs and therefore the cost involved in the treatment.
\end{abstract}

Keywords: Causality, Preventability, Pharmacovigilance, Severity

\section{INTRODUCTION}

WHO defines adverse drug reactions (ADRs) as "a response to a drug which is noxious and unintended and which occurs at doses normally used in man for the prophylaxis, diagnosis, or therapy of disease, or for the modification of physiological function". ${ }^{1}$ ADR is one of the leading causes for morbidity and mortality worldwide. ${ }^{2}$ The overall ADRs rate is estimated to be $6.5 \%$ and $28 \%$ of these are preventable. ${ }^{3}$ Antimicrobials and analgesics are the drugs most frequently responsible for ADRs. However, this pattern and the causative drugs can vary due to different prescribing habits, use of newer drugs and referral bias. ${ }^{4,5}$ Identification and reporting of these ADRs is extremely crucial as it may possibly help the treating physicians on being vigilant while prescribing those drugs and achieving a substantial reduction in healthcare cost. ${ }^{6}$

The spontaneous reporting system has resulted in many marketed drugs being withdrawn for safety concerns. ${ }^{7,8}$ Compared to western countries where ADR reporting is practiced on a regular basis, in India under-reporting of ADRs is a major problem; reasons include lack of time, 
knowledge regarding filling up of the ADR reporting forms and underestimating its importance. ${ }^{9}$ Reporting of ADRs is essential and each treating physicians should consider it as their professional conscientiousness so as to safeguard patients' wellbeing and to reduce the cost involved in patient care. Hence, this study was undertaken to analyse the most common drugs causing ADRs, and to assess the causality, severity and preventability of ADRs in a tertiary care teaching hospital.

\section{METHODS}

This descriptive, observational study was conducted in the Department of Pharmacology in collaboration with clinical departments like General Medicine, Pediatrics, Pulmonary Medicine, Obstetrics and Gynecology, General Surgery, Psychiatry and Dermatology over a period of one year from August 2016 to July 2017 at a tertiary care hospital.

The study was performed in accordance with the Declaration of Helsinki and was initiated following administrative and ethical approvals. Informed consent waiver was obtained from institutional ethics committee as the required information was collected from ADR reports only wherein patients' identity was not revealed.

\section{Study population}

ADR reports of patients from all age groups suspected to be due to medications from the inpatient or outpatient departments of the hospital were included.

\section{Study instrument}

The Central Drug Standard Control Organization (CDSCO) ADR reporting forms were used for collection of data. The forms comprised of patient's demographic details, medication details (name, dose, frequency and route of administration of drug), comprehensive adverse reaction details including description of the reaction, time of onset, duration of the reaction and treatment given along with relevant investigations. Causality assessment was done according to WHO Uppsala Monitoring Centre (UMC) scale. Severity was assessed by modified Hartwig and Siegel scale. Preventability was assessed by modified Schumock and Thornton criteria.

\section{Causality assessment - WHO scale}

The causality categories described by the WHO- UMC are; certain means good temporal association, no other cause, withdrawal response plausible, re-challenge is positive and "definitive" association, probable means good temporal association, other cause unlikely, withdrawal, possible means good temporal association, other causes possible, unlikely means poor temporal association, other causes more likely, unclassified means more data is essential for proper assessment, unclassifiable means insufficient or contradictory information is available. ${ }^{10}$

\section{Severity assessment - Modified Hartwig and Siegel scale}

This scale divides the ADRs into three categories based on severity assessment as mild, moderate and severe. Mild ADRs were defined as those which does not by itself require prolongation of hospitalization and could be managed by simple measures, moderate were those ADRs which needed prolongation of hospital stay of the patient for treatment of the same and severe were life threatening ADRs. ${ }^{11}$

Preventability assessment- Modified Schumock and Thorntons Scale: Modified Schumock and Thornton's criteria have three sections namely definitely preventable, probably preventable and not preventable. ${ }^{12}$

\section{Statistical analysis}

The number of ADR reports and their characteristics were analyzed using descriptive statistics.

\section{RESULTS}

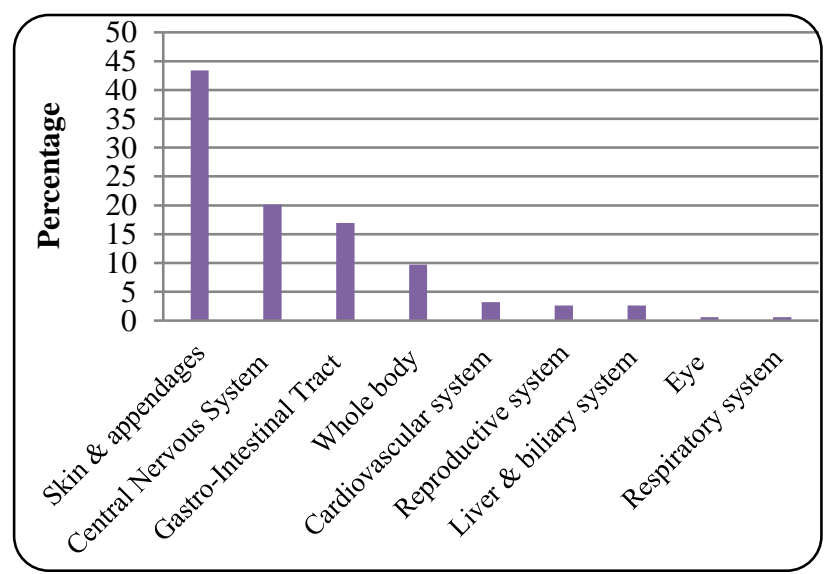

Figure 1: System-wise distribution of ADRs reported in ADR report forms.

Table 1: Distribution of different classes of drugs responsible for causing ADRs.

\begin{tabular}{|ll|}
\hline $\begin{array}{l}\text { Different classes of drugs } \\
\text { causing ADRs }\end{array}$ & $\begin{array}{l}\text { Number of ADRs } \\
\text { N }(\%)\end{array}$ \\
\hline Antimicrobials & $72(46.7)$ \\
\hline $\begin{array}{l}\text { Nonsteroidal anti-inflammatory } \\
\text { drugs }\end{array}$ & $24(15.6)$ \\
\hline Antipsychotics & $14(9.1)$ \\
\hline Hematinics & $13(8.5)$ \\
\hline Multivitamins & $10(6.5)$ \\
\hline Antiepileptics & $5(3.2)$ \\
\hline Antidepressants & $4(2.6)$ \\
\hline Antihypertensives & $4(2.6)$ \\
\hline $\begin{array}{l}\text { Disease modifying antirheumatic } \\
\text { drugs }\end{array}$ & $3(1.9)$ \\
\hline Thrombolytics & $3(1.9)$ \\
\hline Antihistaminics & $2(1.3)$ \\
\hline
\end{tabular}


Among the total 154 ADRs collected 81 (52.6\%) were observed in male patients and $73(47.4 \%)$ in female patients. Out of the total patients, 120 (77.9\%) were observed in adults, $33(21.4 \%)$ in pediatric and $01(0.7 \%)$ in geriatric age group.

Table 2: Reported ADRs with the suspected drugs causing it.

\begin{tabular}{|c|c|}
\hline Type of ADRs & Drugs causing the ADRs \\
\hline Urticarial rash & $\begin{array}{l}\text { Amoxicillin (8), Amikacin (1), Amoxicillin + Clavulanic acid (2), Bromhexine (1), } \\
\text { Carbamazepine (3), Cefotaxime (1), Cefpodoxime (1), Ceftriaoxone (1), } \\
\text { Cotrimoxazole(1), Diclofenac (1), Tenofovir (3), IV Immunoglobulin (1), } \\
\text { Clindamycin (1), Lamivudine (1), Terbinafine (1), Paracetamol (4)Metronidazole (2), } \\
\text { Ornidazole (4), Thalidomide(1), Anti TB regimen include [Isoniazid+ Rifampicin+ } \\
\text { Ethambutol+Pyrazinamide] (4) }\end{array}$ \\
\hline Maculopapular rash & Artemether (3), Haloperidol (1), Paracetamol (1) \\
\hline Erythematous rash & Ketoconazole (1), Ondansetron (2) \\
\hline Exenthematous skin eruption & Cotrimoxazole (2) \\
\hline Angioedema & Tinidazole (1) \\
\hline Steven Johnson's Syndrome & Dapsone (1), Nevirapine (1) \\
\hline Fixed drug eruption & Fluconazole (1), Indomethacin (2) \\
\hline Red man syndrome & Vancomycin (2) \\
\hline Photosensitivity & Griseofulvin (3), Itraconazole (1) \\
\hline Periorbital dermatitis & Chloramphenicol (1) \\
\hline Flushing & Chloramphenicol (1), Tranexamic acid (1) \\
\hline Itching & $\begin{array}{l}\text { Amoxicillin (1), Cefotaxime (1), Lamivudine (1), Paracetamol (6), Anti TB regimen } \\
\text { include [Isoniazid+ Rifampicin+ Ethambutol+Pyrazinamide] (1) }\end{array}$ \\
\hline Headache & $\begin{array}{l}\text { Albendazole (1), Cetrizine (1), Fluconazole (1), Linezolid (1), Kanamycin (1), } \\
\text { Imipramine (1) }\end{array}$ \\
\hline Giddiness & Phenytoin (3), Ibuprofen (2), Fluconazone (2) \\
\hline Hypersomnia & Alprazolam (1) \\
\hline Psychosis & Cycloserine (1) \\
\hline Extrapyramidal reactions & Haloperidol (3), Trifluperazie (2) \\
\hline Akathesia & Haloperidol (2) \\
\hline Orthostatic hypotension & Risperidone (1) \\
\hline Fever & Kanamycin (1) \\
\hline Tinnitus & Streptomycin (1) \\
\hline Nausea and vomiting & Paraaminosalicylic acid (1), Sodium valproate (1), Ibuprofen (2) \\
\hline Diarrhea & Amoxicillin+ Clavulanoc acid (2), Cefixime (3), Methotrexate (1) \\
\hline Oral ulcers & Methotrexate (2) \\
\hline Chills and rigor & Ferrous carboxymaltose (1), Ferrous sucrose (12) \\
\hline Dry cough & Enalapril (1) \\
\hline Hyponatremia & Hydrochlorothiazide (1) \\
\hline Nephrotoxicity & Tenofovir (2) \\
\hline Jaundice & Anti TB regimen include [Isoniazid+ Rifampicin+ Ethambutol+Pyrazinamide] (10) \\
\hline $\begin{array}{l}\text { Hematuria (3), } \\
\text { Petechial hemorrhage (2), } \\
\text { Bleeding gums ( } 3 \text { ) }\end{array}$ & Warfarin (8) \\
\hline Anemia & Azidothymidine (3) \\
\hline Amenorrhea & Risperidone (2) \\
\hline
\end{tabular}

According to WHO Adverse Drug Reaction Terminology (ART) classification of the organ system involvement and types of ADRs, 67 (43.5\%) ADRs involved skin and appendages (cutaneous reactions noted were different types of skin rashes such as maculopapular rash, erythematous rash, urticaria, angioedema, acneiform popular lesions, photosensitivity, Steven Johnson's syndrome and Red Man syndrome). This was followed by symptoms of central nervous system (CNS) involvement such as extra-pyramidal symptoms, giddiness, sedation, 
insomnia, $31(20.1 \%)$, ADRs affecting gastro-intestinal tract (GIT) such as nausea, vomiting, gastritis, diarrhoea, oral ulcer, abdominal pain was found to be $20(16.9 \%)$ Other ADRs reported include hypotension, menstrual irregularities, hematuria, bleeding gums, petechial hemorrhage, hepatitis, dry cough which were less than 5\% of total ADRs reported (Figure 1).

Most common class of drugs which caused the ADRs was antimicrobial agents responsible for 72 (46.7\%) ADRs followed by non-steroidal anti-inflammatory drugs (NSAIDs) for 24 (15.6\%) ADRs (Table 1). Reported ADRs with the suspected drugs causing it is shown in (Table 2).

\section{Causality assessment}

Causality assessment was done for individual cases by using WHO scale. Causality assessment indicated that 106 (68.8\%) ADRs as possible whereas 37 (24\%) ADRs were of probable category. The details of the causality assessment are given in the (Figure 2).

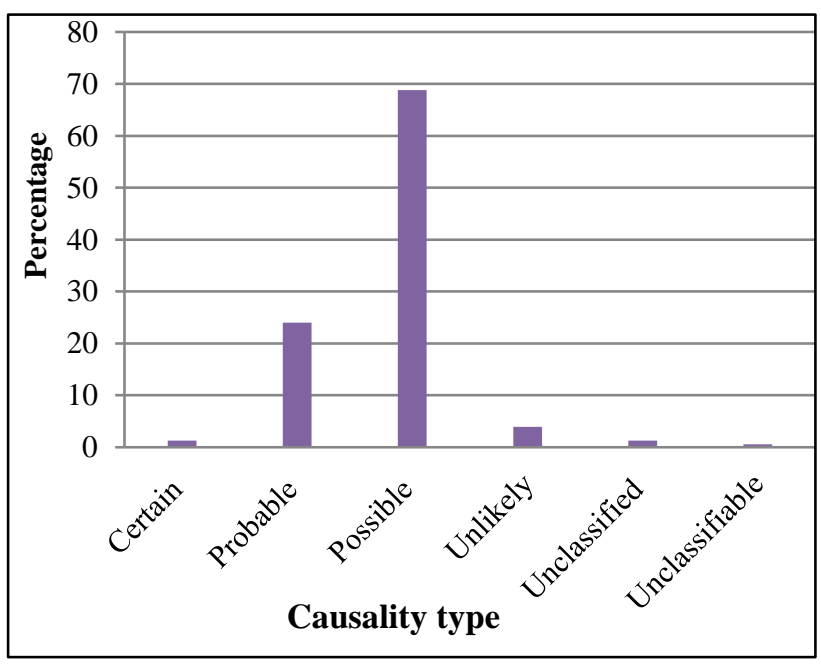

Figure 2: Details of causality assessment using WHO causality assessment scale.

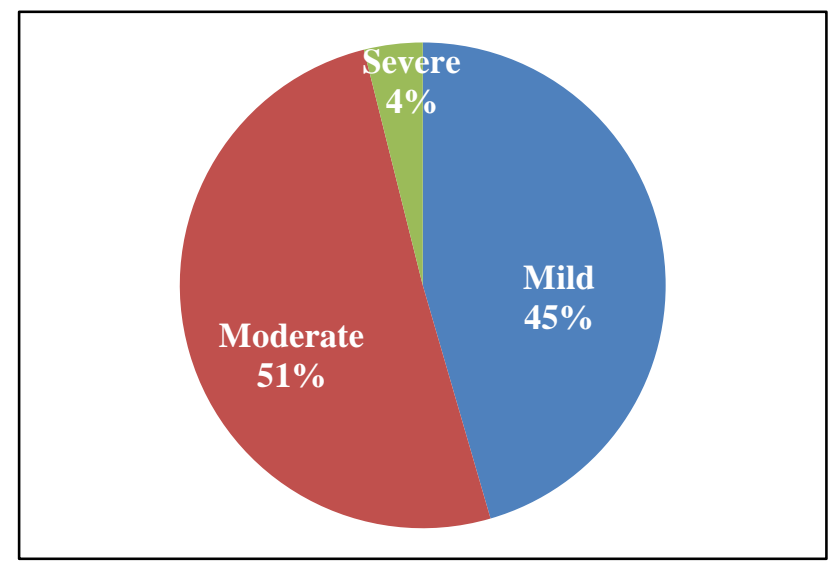

Figure 3: Details of severity assessment by Modified Hartwig and Siegel scale.
Table 3: Details of preventability assessment ADRs using modified Schumock and Thornton scale.

\begin{tabular}{|ll|}
\hline Preventability assessment & Number of ADRs (\%) \\
\hline Definitely preventable & $47(30.5)$ \\
\hline Probably preventable & $24(15.6)$ \\
\hline Not preventable & $83(53.9)$ \\
\hline Total & 154 \\
\hline
\end{tabular}

\section{Severity assessment}

On evaluation of the severity of ADRs by Modified Hartwig and Siegel scale, it was evident that most of the ADRs reported in the study, were of moderate severity followed by mild and severe. Details of the severity assessment are given in the (Figure 3).

\section{Preventability assessment}

On evaluation of the chances of preventability of ADRs using modified Schumock and Thornton scale, it was evident that most of the ADRs reported were not preventable (Table 3).

\section{DISCUSSION}

Spontaneous ADR reporting activity is important to monitor known and unknown adverse effects of medicines. It has played a most important role in the detection of serious and unusual ADRs after marketing when the drug is actually being prescribed by the clinicians. This activity of continuous vigil on the drug related adverse drug reactions has resulted in withdrawal of quite a few drugs in the past such as rofecoxib, cisapride, terfenadine, etc. ADRs have to be considered as one of the major causes of iatrogenic disease with detrimental effect on patient's wellbeing and over-all healthcare system. ${ }^{13}$ The Pharmacovigilance Program of India (PvPI) was launched in the year 2010 with a broad objective to safeguard the health of 1.27 billion people of India. Adverse drug Reactions (ADRs) are reported from all over the country to National Coordinating Centre (NCC)-PvPI, which also work in collaboration with the global ADR monitoring centre (WHO-UMC), Sweden to contribute in the global ADRs database. NCC-PvPI monitors the ADRs among Indian population and helps the regulatory authority of India, Central Drugs Standard Control Organization (CDSCO) in taking decision for the safe use of medicines. Authors conducted this present study at an ADR Monitoring Centre (AMC) of a newly started municipal medical college. With the active involvement from authors' departmental faculty, the clinicians were asked daily about the occurrence of the ADRs in their respective outpatient departments or wards and then the details of the ADRs and the drugs were elicited to gather complete information as asked in the ADR reporting form. This indirectly helped us in increasing awareness and sensitizing the clinicians on reporting of the ADRs noted. 
It was observed that the incidence of ADRs was same in both males and females, finding similar to Jose et al, who reported similar incidence for both genders, though other spontaneous reporting studies in our country had observed high percentage of ADRs in females. ${ }^{13-17}$

In the present study the incidence of ADRs was more in adults which was comparable to the findings reported by various studies, such as Pudukadan et al, Shah et al, Venkatesan et al, Rajkannan et al, and Rao et al, however, contrary to these finding, studies conducted by Ramesh et al, and Arulmani et al, mentioned more incidence of ADRs in elderly patients. ${ }^{14-20}$

Most commonly reported ADRs involved the skin in the form of rashes such as urticaria $(\mathrm{N}=42,62.7 \%)$ which was similar to the findings reported in previous studies. ${ }^{15,17,21}$ This was followed by ADRs related to CNS (20.1\%) and GIT (16.9\%). This finding was comparable to a study by Ramesh et al and Bhabhor et al, and which also showed ADRs involving similar systems. ${ }^{15,22}$ The other system which was found to be involved with regards to the ADR occurrence was gastrointestinal as reported by previous several studies. ${ }^{15,16,19,20}$ In a study conducted by Doshi et al, the author has mentioned that gastrointestinal symptoms occurred most commonly during hospitalization while cutaneous reactions were the most common cause of hospitalization. ${ }^{6}$ No such correlation was observed in this study. Among the cutaneous reactions, urticarial rash was found to be most common ADR in this study, the same has been reported by Doshi et al. Most reactions had sub-acute and latent onset which was similar to the findings reported in previous study. ${ }^{20}$

The major causative class of the drugs responsible for causing ADRs was antimicrobials (46.7\%) followed by NSAIDs (15.6\%). Other epidemiological studies also have reported ADRs due to the same class of drugs. ${ }^{5,13,18,21,23-26}$ Authors observed that among different classes of drugs prescribed, $\beta$ - lactams and fluoroquinolones were most common classes of drugs that caused ADRs. Similar findings were reported by Thong BY et al, and Shamna et al. ${ }^{27,28}$

\section{Causality assessment}

As per WHO causality assessment scale, in present study, it was evident that majority of ADRs belonged to possible category; and seen as those patients were treated with more than five drugs. The multiple medications are important risk factors for drug interactions and ADRs to occur. ${ }^{29}$

\section{Severity assessment}

On evaluation of the severity of ADRs by Modified Hartwig and Siegel scale, it was evident that most of the ADRs reported were of moderate severity $(50.6 \%)$ followed by mild $(45.5 \%)$ and very few were severe (3.9\%). Other study by Ghosh S et al, reported majority
(53\%) of ADRs as moderately severe in nature, but the ADRs in severe category were higher $(25 \%){ }^{25}$

\section{Preventability assessment}

On evaluation of the chances of preventability of ADRs using modified Schumock and Thornton scale, it was evident that $53.9 \%$ ADRs were not preventable, $30.5 \%$ ADRs were definitely preventable and $15.6 \%$ were probably preventable. In present study, a total $46.1 \%$ of the reported ADRs were preventable, which is more than the figures mentioned $(15-37 \%)$ in previous Indian studies. ${ }^{6,17,20}$ Though $54 \%$ of ADRs belong to nonpreventable category, efforts in the direction of precautious and judicious use of antimicrobials and NSAIDs, the most common offending classes of drugs in present set up, perhaps help in substantially reducing the number of preventable ADRs in patients.

\section{CONCLUSION}

The common organ systems showing ADRs with drug use were skin and appendages and central nervous system. The most commonly implicated classes of drugs were found to be $\beta$-lactam group of antibiotics, fluoroquinolones and NSAIDs. The most implicated class of drugs for serious reactions was antimicrobials. Strategies targeting cautious use of these drug classes may help in reducing the number of ADRs and perhaps the associated costs of treatment. Most of the ADRs were of possible category with mild to moderate severity and were non-preventable.

The study had limited number of patient data from tertiary care teaching municipal hospital. Hence, the findings cannot be generalized. Further, in patients on multiple drug prescriptions/polypharmacy, skin allergen tests and oral drug provocations were not performed to confirm the causality and to look safer alternatives.

\section{Future prospects}

The success of a pharmacovigilance program depends upon the active involvement of the healthcare professionals such as doctors, pharmacist, and nurses. Being the key healthcare professionals, providing information on suspected ADRs is as much a moral duty for the doctor as other aspects of patient care. This particular activity helped us in sensitizing the clinicians of authors' institute in reporting of ADRs encountered and above all provided information related to drugs most commonly involved in causing the ADRs, their category and severity. To transform the pharmacovigilance activity into practice, treating physicians need to be educated with regards to importance of reporting predictable as well as unpredictable ADRs. The purposeful pharmacovigilance activity not only will help in identifying some exceptional ADRs not reported in the literature but will also help in generating Indian data on commonly encountered ADRs with specific drugs. 


\section{ACKNOWLEDGEMENTS}

Authors would like to acknowledge all the clinicians from General Medicine, Pediatrics, Pulmonary Medicine, Obstetrics and Gynecology, General Surgery, Psychiatry and Dermatology departments of authors' hospital for providing us the adverse drug reactions.

Funding: No funding sources

Conflict of interest: None declared

Ethical approval: The study was approved by the Institutional Ethics Committee

\section{REFERENCES}

1. Jhansi RK. Review on adverse drug reactions. Adv Pharmacoepidemiol Drug Saf 2015;4;1.

2. Molokhia M, Tanna S, Bell D. Improving reporting of adverse drug reactions: systematic review. Clin Epidemiol. 2009;1:75-92.

3. Raut LA, Patel P, Patel C, Pawar A. Preventability, predictability and seriousness of adverse drug reactions amongst medicine inpatients in a teaching hospital: a prospective observational study. Int $\mathbf{J}$ Pharmaceut Chem Sci 2012;1(3):1293-9.

4. Ding WY, Lee CK, Choon SE. Cutaneous adverse drug reactions seen in a tertiary hospital in Johor, Malaysia. Int J Dermato. 2010 Jul;49(7):834-41.

5. Sharma VK, Sethuraman G, Kumar B. Cutaneous adverse drug reactions: clinical pattern and causative agents- a 6 year series from Chandigarh, India. J Postgrad Med. 2001;47(2):95-9.

6. Doshi MS, Patel PP, Shah SP, Dikshit RK. Intensive monitoring of adverse drug reactions in hospitalized patients of two medical units at a tertiary care teaching hospital. J Pharmacol Pharmacother. 2012;3(4):30813.

7. Mann RD, Andrews EB. Introduction. In: Mann RD, Andrews EB, eds. Pharmacovigilance. 2nd Edition. England: John Wiley \& Sons, Ltd.;2007:3-11.

8. Brown JS, Landry FJ. Recognizing, reporting, and reducing adverse drug reactions. Southern Med J. 2001 Apr;94(4):370-3.

9. Kharkar M, Bowalekar S. Extent of under reporting of Adverse Drug Reactions (ADRs) in India: evaluation using Logistic Regression Analysis (LRA) model. J Clin Trials. 2014;4:155.

10. World Health Organization (WHO). The Importance on Pharmacovigilance. Safety monitoring on medicinal products. Geneva (Switzerland): Office of Publications, World Health Organization; 2002.

11. Hartwig SC, Siegel J, Schneider PJ. Preventability and severity assessment in reporting adverse drug reactions. Am J Health-System Pharmacy. 1992 Sep 1;49(9):2229-32.

12. Lau PM, Stewart K, Dooley MJ. Comment: hospital admissions resulting from preventable adverse drug reactions. Ann Pharmacotherapy. 2003 Feb;37(2):303-4.
13. Jose J, Rao PG. Pattern of adverse drug reactions notified by spontaneous reporting in an Indian tertiary care teaching hospital. Pharmacol Res. 2006;54(3):226-33.

14. David P, DevinderMohan T. Adverse cutaneous drug reactions: Clinical pattern and causative agents in a tertiary care center in South India. Indian J Dermatol Venereol Leprol. 2004 Jan 1;70(1):20.

15. Ramesh M, Pandit J, Parthasarathi G. Adverse drug reactions in a south Indian hospital-their severity and cost involved. Pharmacoepidemiol Drug Safety. 2003 Dec 1;12(8):687-92.

16. Arulmani R, Rajendran SD, Suresh B. Adverse drug reaction monitoring in a secondary care hospital in South India. Br J Clin Pharmacol. 2008;65(2):210-6.

17. Rao PG, Archana B, Jose J. Implementation and results of an adverse drug reaction reporting programme at an Indian teaching hospital. Indian $\mathbf{J}$ Pharmacol. 2006 Jul 1;38(4):293.

18. Shah SP, Desai MK, Dikshit RK. Analysis of cutaneous adverse drug reactions at a tertiary care hospital-a prospective study. Trop J Pharmaceuti Res. 2011;10(4):517-22.

19. Venkatesan R, Ravisankar S, Lakshminarasu M, Rajendran SD. Intensive monitoring of adverse drug reaction in hospitalized patients in a south Indian tertiary care hospital. Int J Pharma Ther. 2014;5:1926.

20. Rajakannan T, Mallayasamy S, Guddattu V, Kamath A, Vilakkthala R, Rao PG, et al. Cost of adverse drug reactions in a South Indian tertiary care teaching hospital. J Clin Pharmacol. 2012;52(4):559-65.

21. Uppal R, Jhaj R, Malhotra S. Adverse drug reactions among inpatients in a north Indian referral hospital. National Med J India. 2000 Jan 1;13(1):16-8.

22. Bhabhor PH, Patel TK, Vahora R, Patel PB, Desai N. Adverse drug reactions in a tertiary care teaching hospital in India: analysis of spontaneously reported cases. Int J Basic Clin Pharmacol. 2014;3:1078-85.

23. Chatterjee S, Ghosh AP, Barbhuiya J, Dey SK. Adverse cutaneous drug reactions: A one year survey at a dermatology outpatient clinic of a tertiary care hospital. Indian J Pharmacol. 2006 Nov 1;38(6):42931.

24. Nandha R, Gupta A, Hashmi A. Cutaneous adverse drug reactions in a tertiary care teaching hospital: A North Indian perspective. Int J Appl Basic Med Res. 2011 Jan-Jun;1(1);50-3.

25. Ghosh S, Acharya LD, Rao PG. Study and evaluation of the various cutaneous adverse drug reactions in Kasturba hospital, Manipal. Indian J PharmSci. 2006;68:212-5.

26. Uchit GP, Shrivastava MP, Badar VA, Navale SB, Mayabhate MM. Adverse drug reactions to antimicrobial agents in a tertiary care hospital in Nagpur. J Indian Med Assoc. 2012;110(4):224-7.

27. Thong BY. Update on the management of antibiotic allergy. Allergy Asthma Immunol Res. 2010;2(2):7786. 
28. Shamna M, Dilip C, Ajmal M, Mohan PL, Shinu C, Jafer CP, et al. A prospective study on Adverse Drug Reactions of antibiotics in a tertiary care hospital. Saudi Pharmaceut J. 2014;22(4):303-8.

29. Jhaveri BN, Patel TK, Barvaliya MJ, Tripathi CB. Drug utilization pattern and pharmacoeconomic analysis in geriatric medical in-patients of a tertiary care hospital of India. J Pharmacol Pharmacother. 2014;5(1):15-20.
Cite this article as: Belhekar MN, Tondare SB, Pandit PR, Bhave KA, Patel TC, Pandey K, Haque A. A prospective study on causality, severity and preventability assessment of adverse drug reactions in a tertiary care hospital in India. Int J Basic Clin Pharmacol 2019;8:104-10. 